\title{
Yihe or Xinghe? A Case Study of Intra-sentence Conjunctions in English-Chinese Legal Parallel Texts
}

\author{
Yan Xi \\ University of Macau
}

\begin{abstract}
In the fields of translation studies in China, there is a perpetual argument regarding Yihe (意合, Parataxis) and Xinghe (形合, Hypotaxis). Most scholars believe that there are more cases of conjunction in the English texts than in the Chinese ones because it is generally considered that Chinese is predominantly paratactic and English mainly hypotactic. Through a case study of explicitation of conjunctions in Chinese-English legal parallel texts, the results show that more intra-sentence conjunctions are used in the two translations than their respective source texts. The notions of Yihe and Xinghe do not seem to account for the increased use of intrasentence conjunctions in legal translation. Instead, explicitation of cohesive devices and grammatical differences between Chinese and English play important roles in more use of intra-sentence conjunctions in legal translation. Through an investigation of Yihe and Xinghe
\end{abstract}

\footnotetext{
* I'd like to express my thanks to Professor Andrew Moody (Univeristy of Macau), Professor Vijay Bhatia (City University of Hong Kong) and Doctor Joseph Park (National University of Singapore) for their comments and advice. The present author is solely responsible for possible errors or mistakes of facts or viewpoints herein.
} 
from the perspective of translation universals, this study aims to test the explanatory force of Yihe and Xinghe in the use of conjunction in legal texts and give a clearer picture of conjunction in Chinese and English legal parallel texts, and therefore will reconstruct the discourse on Chinese and English languages.

Keywords: Yihe, Xinghe, explicitation, conjunction, legal parallel texts

\section{Introduction}

In translation teaching and research in China, scholars seem to have come to agreement as for the general preference for conjunctions used in Chinese and English. There is a widely-held opinion that English makes use of more conjunctions than Chinese because English is mainly a hypotactic language and Chinese predominantly a paratactic language. However, the answer to the extent to which languages are hypotactic or paratactic in given text types is "still surprisingly impressionistic" (Fawcett 1997: 97). Besides, up to now not much detailed contrastive study has been done on conjunction in Chinese/English non-literary texts.

\section{The notions of Yihe (Parataxis) and Xinghe (Hypotaxis)}

The notions of parataxis and hypotaxis are not as popular in the West as the notions of Yihe and Xinghe are in China. Most dictionaries, handbooks and encyclopedias of linguistics and translation studies such as A Glossary of English Grammar edited by Geoffrey Leech, Dictionary of Translation Studies edited by Mark Shuttleworth and Moira Cowie, Routledge Encyclopedia of Translation Studies edited by Mona Baker do not include parataxis and hypotaxis.

In A Comprehensive Grammar of the English Language, Quirk 
et al. (1985) believe that coordination and subordination are "special cases of two types of syntactic arrangement traditionally known as PARATAXIS ('equal arrangement') and HYPOTAXIS ('underneath arrangement')” (918). Nida (2004) put forward three principle methods for clause combination: (1) parataxis; (2) hypotaxis; and (3) protaxis. In his opinion, hypotaxis is a term "used to describe elaborate systems of grammatical subordination, the type of structure so highly developed in literary Greek, and reflected in varying ways in a number of Indo-European languages" (210). Parataxis is used for "combinations of clauses which are closely related semantically, but which have no formal markers” (209-210). Halliday and Hasan (1976) believe that the relationship in a clause complex is either paratactic or hypotactic. Halliday (1994) further points out that all "logical" structures in language are either paratactic or hypotactic. In his opinion, hypotaxis is the relation between a dependent element and its dominant, the element on which it is dependent. Contrasting with this is PARATAXIS, which is the relation between two like elements of equal status, one initiating and the other continuing (218).

As can be seen very clearly, Halliday (1994) views parataxis and hypotaxis mainly as syntactic concepts used to express different ways of linking between clauses or phrases. Hypotaxis is mainly used to express subordination between clauses, though it can be also used to indicate subordination between phrases and parataxis mainly refers to arrangement of constructions such as sentences, clauses and phrases without the use of conjunctions.

In China, Wang $\mathrm{Li}$ is regarded as the first scholar who put forward the terms Yihe and Xinghe (translations for parataxis and hypotaxis). In his opinion, Chinese complex sentences are characterized by parataxis, an unmarked feature in Chinese language where connectives may not be needed, whereas in western languages, hypotaxis is unmarked and connectives are necessary.

After Wang Li, many scholars put forward their new understand- 
dings towards Yihe and Xinghe, and can be divided into two groups. The representatives for the first group include Lian (1993) and Chan (2004), who agree with Western scholars' understandings of parataxis and hypotaxis. Liu (1992) and Pan (1997), the representatives for the second group, tend to view parataxis and hypoxis as basic ways of expression or principles of organization in languages and extend the scope from syntactic levels to other levels in a systematic way.

Beneath the sentence level, scholars tend to agree that Chinese is a paratactic language. Opinions differ when it comes to Chinese and English above the sentence level. Some scholars like Liu (1992) believe that Chinese and English are still characterized by parataxis and hypotaxis above the sentence level. However, Pan (1997) argues that Chinese is hypotactic and English paratactic above the sentence level.

\section{A Case Study}

In this section, a case study of intra-sentence conjunctions will be conducted in order to test the explanatory force of parataxis and hypotaxis in Chinese and English legal texts. Research questions are raised first. This is followed by procedures and methods for this study. Next, data collection is addressed and finally the results of this study are presented with data commentaries.

\subsection{Research Questions for This Study}

The questions to be addressed in this article are what are the characteristics of the use of conjunctions within sentence boundaries in legal translation and what factors influence the use of intrasentence conjunctions in legal translation?

\subsection{Methods}




\subsubsection{Data Collection}

One obvious limitation in the prior studies is the use of unidirectional parallel texts, Chinese source texts and their English translations. As James (1980) points out, the main limitation of these translated texts is "their potential for translation-distortion, that is, the target-language text can show signs of interference from the source-language” (113). In other words, translations reflect not only the features of the target language, but also those of the source language. Many scholars have pointed out the limitations of translated works in contrastive linguistics and proposed the use of bidirectional parallel texts for contrastive textual analysis (e.g. Hartmann 1980; James 1980; Filipovic 1984; Blum-Kulka 2004). Therefore, bidirectional legal parallel texts of the same subject matter will be selected in this analysis. Bidirectional legal parallel texts refer to Chinese legal texts with their English translations, and English legal texts with their Chinese translations. Besides, these legal texts are all of the same subject matter.

Four legal texts about arbitration rules were selected for this research: China International Economic and Trade Arbitration Commission (CIETAC) Arbitration Rules (2005) in Chinese (hereinafter referred to as PRC-C), the English translation of PRC-C (hereinafter referred to as PRC-E), Arbitration Rules issued by United Nations Commission on International Trade Law (UNCITRAL) in English (hereinafter referred to as UN-E), and the Chinese translation of UN-E (hereinafter referred to as UN-C).

PRC-C was promulgated by the China Council for the Promotion of International Trade on January 11, 2005 and was effective as of May 1, 2005. Both Text A and its translation, PRC-E, were selected from Isinolaw.com, a database the library of the University of Macau subscribes to. PRC-C is translated and provided by the International Economic Affairs Department of the Ministry of 
142 Yihe or Xinghe? A Case Study of Intra-sentence Conjunctions

Foreign Trade and Economic Commission (MOFTEC) under the State Council. UN-E was issued by United Nations Commission on International Trade Law (UNCITRAL) on April 28, 1976 and adopted by United Nations on December 15, 1976. Both UN-E and its translation UN-C were selected from Selected Readings on Laws and Practices in International Trade (1986).

\subsubsection{Procedures and Methods}

Three procedures are adopted in this case study: 1) occurrences of conjunctions between clauses; 2) calculation of the number of clauses, sentences, English words and Chinese characters; 3) indices of comparison.

In previous contrastive studies between Chinese and English, only tokens/words and tokens/characters were used for contrastive analysis. The primary limitation of this method is that there tends to be more Chinese characters than English words because the greatest number of Chinese words is compound words which are composed of more than one Chinese character. This method could not entirely reflect the real differences between Chinese and English textual characteristics. Instead, it reflects the typological differences between English and Chinese. Therefore, three methods, tokens/sentence, tokens/clause, tokens/words or tokens/characters, are adopted in the present study in order to find the real differences between Chinese and English.

\subsection{Results}

Table 1 provides the number of conjunctions used in adjunct clauses within sentence boundaries in Chinese and English legal texts. As can be seen in Table 1, Chinese legal source text makes use of 88 conjunctions and its English translation 125 conjunctions. 87 conjunctions are used in English legal source text and 104 in its 
Chinese translation. On the whole, both Chinese and English legal texts make use of many intra-sentence conjunctions. More importantly, more conjunctions are used in the two translations than their respective source texts. This is quite different from previous contrastive studies of conjunction in Chinese and English literary texts where there are more cases of conjunction in English literary texts than in Chinese ones.

Table 1. The Occurrence of Intra-sentence Conjunctions in Chinese and English Legal Texts

\begin{tabular}{|c|c|c|c|c|}
\hline & $\begin{array}{c}\text { Text A } \\
\text { PRC-C }\end{array}$ & $\begin{array}{c}\text { Text B } \\
\text { PRC-E }\end{array}$ & $\begin{array}{c}\text { Text C } \\
\text { UN-C }\end{array}$ & $\begin{array}{c}\text { Text D } \\
\text { UN-E }\end{array}$ \\
\hline \hline $\begin{array}{c}\text { Number of intra- } \\
\text { sentence conjunctions }\end{array}$ & 88 & 125 & 104 & 87 \\
\hline Number of clauses & 793 & 779 & 574 & 536 \\
\hline Number of sentences & 269 & 262 & 172 & 169 \\
\hline $\begin{array}{c}\text { Number of words or } \\
\text { characters }\end{array}$ & 12285 & 8721 & 8000 & 5731 \\
\hline Ratio of tokens/clause & 11.10 & 11.81 & 18.12 & 16.23 \\
\hline Ratio of tokens/sentence & 32.71 & 35.11 & 60.47 & 51.48 \\
\hline $\begin{array}{c}\text { Ratio of tokens/10,000 } \\
\text { words or characters }\end{array}$ & 71.63 & 105.49 & 180 & 151.81 \\
\hline
\end{tabular}




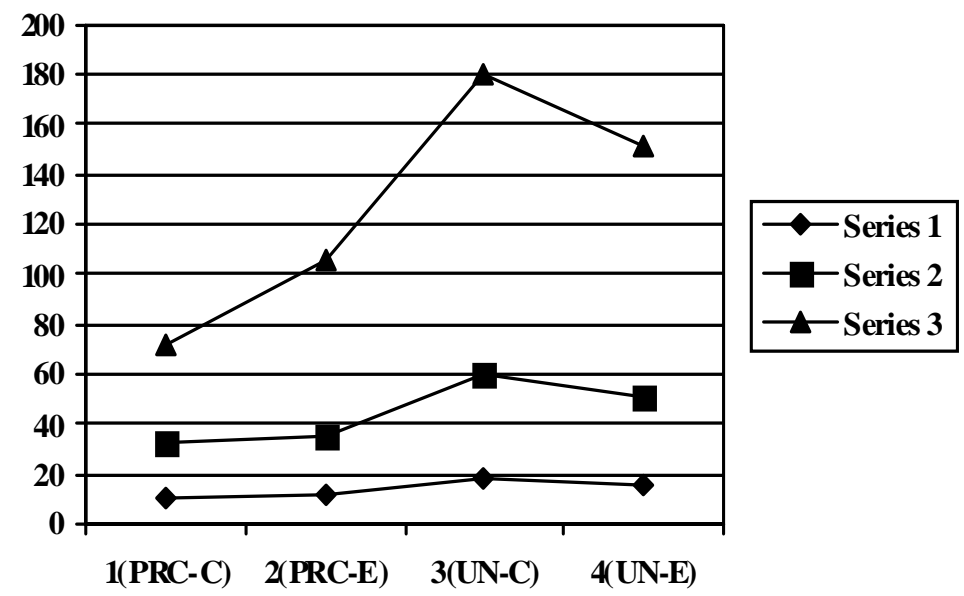

Series $1=$ ratio of tokens per clause, Series $2=$ ratio of tokens per sentence, Series $3=$ ratio of tokens per 10,000 words/characters

Fig. 1. Line Graph of Intra-sentence Conjunctions in Legal Texts

The results of the use of intra-sentence conjunctions in the selected legal texts are set out in the line graph of Fig. 1. As has been pointed out in 3.2.2, there are more Chinese characters than English words, so the method of ratio of tokens per 10,000 words/ characters could not fully reflect the real differences between Chinese and English languages. Series 1 and 2 in Fig. 1 seem to show that more intra-sentence conjunctions are used in English translation than Chinese legal text. We can also see that there are more intra-sentence conjunctions in Chinese translation than English translation, but that does not seem to be a great difference according to these two indices (tokens/clause and tokens/sentence). 
Table 2. The Chi-square Correlation Test of Significance of Intrasentence Conjunctions

\begin{tabular}{|c|c|c|c|}
\hline & Tokens/Clause & Tokens/Sentence & Tokens/Words \\
\hline $\begin{array}{c}\text { Difference between } \\
\text { Chinese S/T }\end{array}$ & 0.23416932 & 0.1229456 & 0.24907576 \\
\hline $\begin{array}{c}\text { Difference between } \\
\text { English S/T }\end{array}$ & 0.25578586 & 0.13784508 & 0.30997201 \\
\hline $\begin{array}{l}\text { S=Source text, T } \\
\text { probability) }\end{array}$
\end{tabular}

The results of Chi-square correlation test are presented in Table 2. As can be seen from this table, in terms of the use of intrasentence conjunctions in legal texts, there are no statistically significant differences between Chinese source text and its translation, as well as between English source text and its translation.

\section{Discussion}

Linguistic differences such as grammatical differences play an important rule in more use of intra-sentence conjunctions in legal translation. Chinese and English languages are different in some aspects of their grammatical systems such as different ways of expressing conjunctive relations in Chinese and English legal texts. For example, “的” is frequently used in Chinese legal texts to serve as indicators of condition and hypothesis, but conjunctions are usually used in English legal texts to indicate cases of condition and hypothesis. For instance, in examples (1) and (2) selected from the CIETAC Arbitration Rules and its English translation, de (的) is rendered into English conjunction "where”.

（1a）仲裁协议或合同中的仲裁条款订明由中国国际经济贸 易仲裁委员会或其分会仲裁或使用其旧名称为仲裁机 
构的, 均应视为双方当事人一致同意由仲裁委员会或 其分会仲裁。(Article 2.3, the CIETAC Arbitra-tion Rules) Zhongcai xieyi huo hetong zhong de zhongcai tiaokuan dingming you zhongguo guoji jingji maoyi zhongcai weiyuanhui huo qi fenhui zhongcai huo shiyong qi jiumingcheng wei zhongcai jigou de, junying shiwei shuangfang dangshiren yizhi tongyi you zhongcai weiyuanhui huo qi fenhui zhongcai.

Arbitration agreement or contract middle DE arbitration articles provide up to China international economic trade arbitration commission or his Sub-Commission arbitration or use his old name be arbitration organ DE, should regard two parties unanimously agree up to Arbitration Commission or his Sub-Commission arbitrate.

(1b) Where an arbitration agreement or an arbitration clause contained in a contract provides that the arbitration shall be conducted under auspices of the China International Economic and Trade Arbitration Commission or one of its Sub-Commissions or the organization with one of its former names, it shall be deemed that the parties have unanimously agreed that the arbitration shall be conducted under auspices of the Arbitration Commission or by its Sub-Commissions.

（2a）当事人在仲裁协议或合同中的仲裁条款订明由中国国 际贸易促进委员会/中国国际商会仲裁或由中国国际贸 易促进委员会/中国国际商会的仲裁委员会或仲裁院仲 裁的, 均应视为双方当事人一致同意由中国国际 经济 贸易仲裁委员会仲裁。(Article 2.4, the CIETAC Arbitration Rules)

Dangshiren zai zhongcai xieyi huo hetong zhong de 
zhongcai tiaokuan dingming you zhongguo guoji jingji maoyi cujing weiyuanhui /zhongguo guoji shanghui zhongcai huo you zhongguo guoji maoyi cujing weiyuanhui/zhongguo guoji shanghui de zhongcai weiyuanhui huo zhongcaiyuan zhongcai de, junying shiwei shuangfang dangshiren yizhi tongyi you zhongguo guoji jingji maoyi zhongcai weiyuanhui zhongcai.

Parties in arbitration agreement or contract middle DE arbitration articles provide up to China international economic trade promote commission/China international chamber arbitrate or up to China international trade promote commission/China international chamber DE arbitration commission or arbitration institute arbitrate $\mathrm{DE}$, should regard two parties unanimously agree up to China international economic trade arbitration commission arbitrate.

(2b) Where an arbitration agreement or an arbitration clause contained in a contract provides that the arbitration shall be conducted under auspices of the China Council for the Promotion of International Trade/China Chamber of International Commerce or the arbitration commission or arbitration institute of the China Council for the Promotion of International Trade/China Chamber of International Commerce, it shall be deemed that the parties have unanimously agreed that the arbitration shall be conducted under auspices of China International Economic and Trade Arbitration Commission.

Like legal Chinese, indicators of condition and hypothesis in English legal texts can be also realized in different ways. In addition to conjunctions, other devices such as prepositional phrases can indicate cases of condition and hypothesis in English legal texts. 
148 Yihe or Xinghe? A Case Study of Intra-sentence Conjunctions

However, only conjunctions could be used in Chinese legal translation. For instance, in examples (3) and (4) selected from the UNCITRAL Arbitration Rules and its Chinese translation, prepositional phrase "in the event of" is used instead of "if" in the UNCITRAL Arbitration Rules, and prepositional phrase is translated into “如果 (ruguo, if)" in Chinese translation.

(3a) In the event of the death or resignation of an arbitrator during the course of the arbitral proceedings, a substitute arbitrator shall be appointed or chosen pursuant to the procedure provided for in articles 6 to 9 that was applicable to the appointment or choice of the arbitrator being replaced. (Article 13, the UNCITRAL Arbitration Rules)

(3b) 如果仲裁员在仲裁程序期间死亡或辞职，则应按照 第六条至第九条所规定适用于指定或遴选被更换仲 裁 员的程序指定或遴选一名替代仲裁员。

Ruguo chongcaiyuan zai zhongcai chengxu qijian siwang huo cizhi, ze ying anzhao diliutiao zhi dijiutiao suoguiding shiyongyu zhiding huo linxuan bei genghuan chongcaiyuan de chengxu zhiding huo linxuan yiming tidai zhongcaiyuan.

If arbitrators in arbitration procedure period die or resign, then should according to the sixth article to the ninth article stipulated applicable designated or chosen by change arbitrators DE procedure designate or choose one substitute arbitrator.

(4a) In the event of an oral hearing, the arbitral tribunal shall give the parties adequate advance notice of the date, time and place thereof. (Article 25, the UNCITRAL Arbitration Rules) 
(4b) 如果需进行口头审理, 仲裁庭应在事先足够的时间 将其日期, 时间和地点通知当事人各方。

Ruguo хи jinxing koutou shengli, zhongcaiting ying zai shixian zugou de shijian jiang qi riqi, shijian he didian tongzhi dangshiren gefang.

If need proceed oral hearing, arbitral tribunal should in prior enough DE time use his date, time and place inform parties each side.

Apart from grammatical differences of Chinese and English, explicitation is another important factor in more use of intra-sentence conjunctions. Explicitation is an important feature of translation universals. Blum-Kulka (1986/2004) puts forward "the explicitation hypothesis", which postulates "an observed cohesive explicitness from SL to TL texts regardless of the increase traceable to differences between the two linguistic and textual systems" (292). He further states:

The process of translation, particularly if successful, necessitates a complex text and discourse processing. The process of interpretation performed by the translator on the source text might lead to a TL text which is more redundant than the SL text. This redundancy can be expressed by a rise in the level of cohesive explicitness in the TL text. (292)

In other words, the increased use of cohesive devices in translation, according to Blum-Kulka, is an inherent cognitive and translation strategy universally adopted to facilitate translation from Source Text to Target Text, either from Chinese to English or from English to Chinese. Legal translation is without exception. The solemnity of law requires that the legal translation should be faithful to the source text. Therefore, it seems that the best solution for legal translators is to strictly follow the patterns of cohesive devices, such as conjunctive elements in the source text, so that the original relation between 
150 Yihe or Xinghe? A Case Study of Intra-sentence Conjunctions

terms and clauses in legal source texts would not be distorted. However, explicitation of conjunctions does exist in legal translation. For instance, in examples (5) and (6) selected from the CIETAC Arbitration Rules and its English translation, intra-sentence conjunction "while” and "if” are added respectively.

（5a）仲裁委员会主任履行本规则赋予的职责，副主任根 据主任的授权可以履行主任的职责。(Article 2.5, the CIETAC Arbitration Rules)

Zhongcai weiyuanhui zhuren lüxing ben guize fuyu de zhize, fu zhuren genju zhuren de shouquan keyi lüxing zhuren de zhize.

Arbitration commission director perform this rule confer DE duty, vice director according to director DE empowerment may perform director DE duty.

(5b) The Chairman of the CIETAC shall perform the functions and duties vested in him/her by these Rules while a Vice-Chairman may perform the Chairman's functions and duties with the Chairman's authorization.

(6a) 符合本规则第五十条规定的国内仲裁案件, 适用第 四章简易程序的规定。(Article 59.2, the CIETAC Arbitration Rules)

Fuhe ben guize diwushitiao guiding de guonei zhongcai anjian, shiyong disizhang jianyi chengxu de guiding. Agree this rule the fiftieth article provision DE domestic arbitration case, apply the fourth chapter simple procedure DE provision.

(6b) The provisions of the Summary Procedure of Chapter IV shall apply if a domestic arbitration case falls within the scope of Article 50 of these Rules. 
Blum-Kulka (1986) points out two reasons for explicitation: differences of two languages in stylistic preferences and explicitation inherent in the translation process. Although it is generally accepted that Chinese is predominantly a paratactic language while English mainly a hypotactic one, this stylistic difference does not seem to have much explanatory power for the explicitation of conjunction not only in English translation of Chinese legal texts but also in Chinese translation of English legal texts. For instance, in examples (7) and (8) selected from the UNCITRAL Arbitration Rules and its Chinese translation, intra-sentence conjunctions “如 (ru, if)” and “但 (dan, however)" are added respectively.

(7a) 如果任何一方当事人在仲裁程序任何一个阶段请求 仲裁庭举行审理，仲裁庭应即照办，以便由包括专家 证人在内的证人提供证据或进行口头辩论。如无此 种请求, 仲裁庭应决定是否举行这种审理, 或仲裁程 序是否根据文件和其他资料进行。(Article 15.2, the UNCITRAL Arbitration Rules)

Ruguo renhe yifang dangshiren zai zhongcai chengxu renhe yige jieduan qingqiu zhongcaiting juxing shengli, zhongcaiting ying ji zhaoban, yibian you baokuo zhuanjia zhengren zainei de zhengren tigong zhengju huo jinxing koutou bianlun. $R u$ wu cizhong qingqiu, zhongcaiting ying jueding shifou juxing zhezhong shengli, huo zhongcai chengxu shifou genju wenjian he qita ziliao jinxing.

If any one side party in arbitration procedure any one stage request arbitral tribunal hold hearing, arbitral tribunal should immediately do as told, so that by include expert witnesses in DE witnesses provide evidence or proceed oral debate. If without such request, arbitral tribunal should decide whether hold such hearing, or arbitration procedure whether according to document and other materials proceed. 
152 Yihe or Xinghe? A Case Study of Intra-sentence Conjunctions

(7b) If either party so requests at any stage of the proceedings, the arbitral tribunal shall hold hearings for the presentation of evidence by witnesses, including expert witnesses, or for oral argument. In the absence of such a request, the arbitral tribunal shall decide whether to hold such hearings or whether the proceedings shall be conducted on the basis of documents and other materials.

(8a) 关于程序问题, 如果不能获得多数或仲裁庭授权首 席仲裁员得自行决定，但仲裁庭可以修正。(Article 31.2, the UNCITRAL Arbitration Rules)

Guanyu chengxu wenti, ruguo bu neng huode duoshu huo zhongcaiting shouquan shouxi zhongcaiyuan dei zixing jueding, dan zhongcaiting keyi xiuzheng.

About procedure issue, if not able get major or arbitral tribunal empower chief arbitrator have to of himself decide, but arbitral tribunal may modify.

(8b) In the case of questions of procedure, when there is no majority or when the arbitral tribunal so authorizes, the presiding arbitrator may decide on his own, subject to revision, if any, by the arbitral tribunal.

The above data seem to prove that explicitation is a prominent feature and a universal strategy in the translation process.

To sum up, on one hand, adjustments of conjunctions should be made in legal translation according to the grammatical differences between the Chinese and English languages in expressing conjunctive relations, such as de “的” is translated into conjunction "where" and the prepositional phrase "in the event of" is translated into conjunction ruguo (如果) 'if'. On the other hand, explicitation of intra-sentence conjunctions exists in legal translation and is a universal strategy adopted by legal translators. 


\section{Conclusion}

Through a contrastive study of intra-sentence conjunctions in Chinese and English legal texts, the results show that more conjunctions are used not only in Chinese-English legal translation, but also in EnglishChinese legal translation. As for the increased use of conjunctions in legal translation, the notions of Yihe and Xinghe do not seem to account for the increased use of intra-sentence conjunctions in legal translation. Instead, the different ways of expressing conjunctive relations between Chinese and English and the explicitation of cohesive devices in legal translation play an important role in the more use of intraconjunctions in Chinese-English and English-Chinese legal translation.

Some limitations exist in the present study. First of all, there are different kinds of English legal texts in different legal systems, such as civil law and common law. The scope of the present study is restricted to arbitration rules in civil code legal system. Second, apart from legal texts, other text types, such as literary texts, also need further exploration to test the explanatory force of hypotaxis and parataxis in Chinese and English languages both above the sentence level and below the sentence level. Third, the data at our disposal is not substantial. It is necessary to build a corpus of bidirectional parallel texts of various text types and carry out a largescale contrastive analysis for explicitation studies. In one word, there are many areas which need improvements and explorations in order to better understand the notions of Yihe and Xinghe as well as translation universals.

\section{References}

Blum-Kulka, S. 2004. Shifts of Cohesion and Coherence in Translation. In L. Venuti (ed.), The Translation Studies Reader. London: Routledge, 290-305.

Chan, S. W. 2004. A Dictionary of Translation Technology. Hong 
154 Yihe or Xinghe? A Case Study of Intra-sentence Conjunctions

Kong: The Chinese University Press.

Fawcett, P. 1997. Translation and Language: Linguistic Theories

Explained. Manchester: St. Jerome Publishing.

Filipovic, R. 1984. What Are the Primary Data for Contrastive

Analysis? In J. Fisiak (ed.), Contrastive Linguistics: Prospects and Problems 107-117. Berlin: Mouton.

Halliday, M. 1994. An Introduction to Functional Grammar (2nd edition). London: Edward Arnold.

Halliday, M. \& Hasan, R. 1976. Cohesion in English. London: Longman. Hartmann, R. 1980. Contrastive Textology: Comparative Discourse Analysis in Applied Linguistics. Heidelberg: Julius Groos Verlag. James, C. 1980. Contrastive Analysis. London: Longman.

Lian, S. 1993. Contrastive Studies of English and Chinese. Beijing: Higher Education Press.

Liu, M. 1992. Contrastive Studies of Chinese and English for Translation. Nanchang: Jiangxi Education Publishing House.

Nida, E. 2004. Toward a Science of Translating. Shanghai: Shanghai Foreign Language Education Press.

Pan, W. 1997. Hanying duibi gangyao. (Essentials of Contrastive Studies of Chinese and English). Beijing: Beijing Language and Culture University Press.

Quirk, R. et al. 1985. A Comprehensive Grammar of the English Language. London: Longman.

Qian, Y. et al. (eds.) 1986. Selected Readings on Laws and Practices in International Trade. Beijing: University of International Business and Economics Press.

Wang, L. 1959. Modern Chinese Grammar. Hong Kong: Chung Hwa Book Corp.

Yan Xi

Department of English, University of Macau

Av. Padre Tomas Pereira, Taipa, Macau, China

Phone: 83-97-4418; Email: yxmax1980@126.com

Received in Dec, 2009; Reviewed in Feb, 2010; Revised version received in Mar, 2010 